\title{
Flight to Quality? An Investigation of Changing Price Spreads in Commercial Real Estate Markets
}

\author{
by
}

Franz Fuerst*

Patrick McAllister**

Petros Sivitanides***

Working Paper

* University of Cambridge, Department of Land Economy, Cambridge CB3 9EP, UK **University College London, The Bartlett School of Planning, London

*** AXA Real Estate, London 


\begin{abstract}
This paper uses sales transaction data in order to examine whether flight from risk phenomena took place in the US office market during the financial crisis of 20072009. The effect of the crisis on the pricing of asset quality attributes is investigated. Hedonic regression procedures are used to test the hypothesis that the spread between the pricing of low quality and high quality characteristics increased during the crisis period compared to the pre-crisis period. The results of the hedonic regression models suggest that the price spread between Class $A$ and other properties grew significantly during the downturn.
\end{abstract}




\section{Introduction}

Associated with interlinked macro-economic and capital market episodic crises, in severe disruptions to credit markets there can be "flight to quality" and/or "flight to liquidity”. Such episodes are associated with falls in asset values and widening risk spreads between different qualities of assets within and between the major asset classes. This paper investigates the extent to which, as market conditions change, differences in risk premia between different qualities of real estate asset will also lead to changes in price spreads. There has been considerable empirical research regarding the occurrence of flight to quality or liquidity phenomena in stock and bond markets but there has been little, if any, research regarding this issue in the commercial real estate market.

This paper investigates whether there is evidence to support the expectation that, during market downturns, due to increases in investors' risk aversion and the inherent risk of the assets themselves, there are differences in pricing effects between low quality and high quality properties. It is expected that, due to changes in investor demand, high quality properties become relatively more liquid and that the price spread between different qualities of real estate asset increases in market falls to reflect the divergence in the risk premium attached to these qualities. Within the framework of hedonic price analysis, this would imply a significant change in the coefficients of the quality indicator contributing to the total price of a particular property. 
Given the basic proposition of the paper, the remainder of the analysis is structured as follows. The first part of the paper discusses related research on this topic and evaluates the concept of quality in the context of commercial real estate markets. This is followed by a discussion of the data and empirical approach. Next, we use hedonic regression to test the hypothesis that the spread between the pricing of low quality and high quality characteristics increased during the crisis period compared to the pre-crisis period. Our expectation is that there will be significant increases in the differences between the coefficients for Class A and other assets. Given some concerns about CoStar ratings, we use an ordered logistic regression to generate alternative quality scores for each asset and estimate whether the observed price difference between high and low quality assets changed significantly during the market downturn. Finally, conclusions are drawn.

\section{Related Literature}

Similarly to credit ratings but much less formal, in commercial real estate markets assets are conventionally ranked into categories. Such groupings are often a function of a bundle of attributes which interact to form, a perhaps somewhat nebulous concept, investment quality. One of the most important determinants of investment quality is the credit risk of the income stream. This is largely driven by the financial strength of the tenants and the terms of the lease contracts (particularly period remaining on the lease). In addition, the physical attributes of the asset in terms of its suitability for business occupation (associated with specification, appearance, configuration, interior finishing, etc) are crucial 
determinants of an asset's ability to attract occupiers with low credit risk and who accept lease terms that are relatively less risky for the owner. Further, locational differences within and between office markets will also be an important determinant of investment quality. Albeit often intuitively, these attributes are implicitly weighted by market intermediaries and used to provide relatively simple metrics of investment quality that can often act as heuristic cues for investors.

In the idiom of the commercial real estate market, investment quality is often discussed in terms of whether assets can be classified as Class A, B or C. Similar segmentation is also often highlighted between investor types. Short-hand clientele investor categories, such as institutional/non-institutional and core/value/opportunistic reflect variations in risk preferences amongst investor groups. Indeed, assets are also classified in the same way. There tends to be crosssectional and time-varying differences in marginal investors for real estate assets with different investment qualities. As noted above, the objective of this paper is to investigate the extent to which spreads between different qualities of real estate assets change significantly during different market regimes.

There is a longstanding body of research on credit spreads in bond markets investigating the drivers of changes in risk premia in market crises (see Vayanos, 2004 for a review). This literature identifies changes in a common component of the risk premium associated with 'general' risk aversion as one driver of yield spreads. In practice, changes in general risk aversion are not directly observable and it is only the asset class risk premium that is available. This is a function of a common component (the common price of risk) and the inherent riskiness of that asset class. 
Within the bond spread literature, the inherent riskiness of the asset class is decomposed into two other components. The first is associated with a change in the risk of the asset class itself produced by deteriorating economic and market conditions leading to an increase in default risk. For instance, in commercial real estate markets, weak market conditions can result in higher risk of tenant default, lease terminations and voids. The second component is related to changes in investors' risk preferences.

Further, in a flight from risk, certain clientele groups may be differentially affected. For instance, in periods of restricted credit, lower quality borrowers may be unable to borrow with consequent effects on the level of demand in their segment. A third determinant of an increase in the yield spread is a change in liquidity. Changes in market conditions cause changes in investors' liquidity preferences and in the relative liquidity of different asset types. While it is problematic to draw analogies from the actively traded, public bond markets with thinly traded, private real estate markets, for both there tends to be a positive association between asset liquidity and asset quality.

There is a body of work that has investigated the linkages between bond and stock market performance in market crises. There are two competing views regarding the co-variance of the higher-risk stocks and the lower-risk government bonds with changing market conditions. According to Durand, Junker and Szimayer (2007), a positive co-variance between these two asset classes can be justified theoretically on the basis of the argument that when interest rates are higher and bond returns are lower, stock returns should also be lower, as expected future cash flows are 
discounted using higher discount rates, which result in lower net present values. Furthermore, expected future cash flows are lower during periods of higher interest rates further reducing net present value. On the other hand, the flight-to-quality phenomenon implies that in a high-risk environment, when investors liquidate their stock positions to purchase safer investments such as government bonds, stock and bond returns should be negatively correlated. The expectations for real estate markets are equally ambiguous. It is possible that, since they can be more easily sold, high quality real estate assets may be liquidated in a flight to high quality bonds. Alternatively, funds flows to high quality real estate assets may increase as a proportion of total flows to real estate funds.

Durand, Junker and Szimayer (2007), who analyzed quarterly returns from 1952 to 2003, found evidence that supports both of these competing views regarding investor behaviour. In particular, they verified that during non-dramatic economic conditions stock and bond returns were positively correlated. However, supporting the flightto-quality hypothesis they also found evidence that, in some "extreme" situations, this relationship turned negative. Hartmann, Straetmans and de Vries (2004), found that flight of capital from the stock market to government bonds during crashes is as common as both markets (stocks and bonds) co-crashing at the same time.

For Euro area bond markets, Barrios et al., examined government bond spreads during the financial crisis of 2008. Their findings point to risk aversion and resulting flight-to-safety and flight-to-liquidity phenomena in capital markets as one of the three determinants of yield spreads. Their findings suggest that the 
additional interest rate premium of new bond issues increased during periods characterized by a high level of risk aversion.

In the real estate literature, there have been no studies explicitly investigating the 'flight to quality' issue. Focusing on turnover and liquidity, a number of studies have examined whether there are systematic differences between sold and unsold properties (see Guilkey et al, 1989; Collett et al, 2003; Fisher et al, 2003, Fisher et al, 2004; and Johnson, Benefield and Wiley 2007). Broadly, studies find that age (the closest proxy for quality in the studies) has a negative impact on probability of sale. From the perspective of this study, Fisher et al, (2003) draw an important distinction between liquidity and transaction frequency. This is a potentially important issue since properties may not transact either because they are difficult to sell (can't sell) or because the owner does not wish to sell (won't sell). Hence, a decision not to sell may be associated either with negative or with positive asset attributes. For instance, the low transaction frequency identified by Collett et al (2003) for retail warehouses in the UK was almost certainly due to positive attributes rather than negative factors. Conversely, most studies cited above found that small lots had a higher likelihood of sale than larger lot sizes. However, this may not indicate differential liquidity. Rather, since the sample periods coincided with a portfolio restructuring towards larger lots by investing institutions, it may imply differences in motivation to sell rather than ability to sell.

The literature on real estate index construction has generated a substantive body of work focused on potential bias due to variable liquidity and sample selection bias. 
Work in the residential sector by Gatzlaff and Haurin (1997 and 1998) in particular highlighted the potential for indexes to record biased measures of market price shifts due to differences in sale probability between high and low quality assets. With Fisher and Geltner, this work was extended into the commercial real estate sector (see Fisher, Gatzlaff, Geltner and Haurin, 2003 and 2004). The emphasis in this body of work was on the development of alternative real estate indices that could control for differences in the quality of building sold in different market regimes. Their results suggested that because transacted properties did not provide a random sample of all properties, it was important to control for intertemporal differences in liquidity among assets in index construction.

The 'flight to quality/liquidity' literature exhibits some of the fundamental problems in investigating the relationship between capital flows and returns. It has been pointed out that capital 'flights' do not subtract capital from the overall market since other investors are taking the other side of the transaction (Shiller, 1998). Indeed, Zheng (1998) argues that the existence of a seller for every buyer means that flow of funds analysis is simply a means of identifying which group or sector moves market prices i.e the marginal investor(s). Another similarity is that there are conflicting expectations of the flow-return relationships in the capital flows literature. This study generates similar potentially countervailing expectations. In a market crisis, a flight to high quality bonds from the real estate sector may result in Class A properties being sold. However, a flight to bonds from real estate may be dominated by a flight to quality effect within the real estate asset class. Alternatively, investors may wish to retain high quality assets in their real estate portfolios and dispose of Class B or Class C assets. Similar to the capital flows 
literature, it is difficult to generate consistent a priori expectations. Bearing this in mind, we present the empirical framework and results below.

\section{Data and Empirical Model}

The study draws on CoStar's comprehensive national commercial real estate database which includes approximately 43 billion square feet of commercial space in more than two million properties making it the largest available real estate database in the United States. For researchers, it has become an increasingly important source of data on real estate assets and transactions. In total, our database comprises of 18,562 observations in the 2000 to 2010 period.

There are a number of important data issues to acknowledge. CoStar was founded in 1987. Since this period, its coverage of the US commercial real estate sector has been increasing in terms of its scale and scope. It is expected that it would have initially prioritized higher quality offices in the main urban centers. As a result, change in absolute numbers of transactions may not be a reliable indicator of the different turnover rates in different years. For instance, increased numbers of Class B sales in a given year may be due to growth in the coverage of CoStar as well as variations in turnover rates between different quality categories. Put simply, the proportion of sales of Class B and C offices may have increased in the sample period because CoStar increased their coverage of this quality of asset. As a result, it is important to be cautious when interpreting changes in sale volumes. 
Clearly, the measurement of quality is central to this paper. As noted above, it is standard market practice to use ordinal rankings (e.g. Class A, B or C or prime, secondary, tertiary) in commercial real estate markets. However, the use of such simple categories is not without problems. Such categories are composite indicators that incorporate a number of attributes of real estate assets - age, construction, location, building services inter alia. The CoStar definitions confirm this point (see Appendix 3). In the past, CoStar building ratings have been subject to criticism about their subjectivity (see Scheff, 2006). It is apparent from CoStar's response to this criticism that it is Costar who allocates the categories to the offices. This is not surprising given the incentives for leasing brokers and owners themselves to achieve a high rating. In addition, the extent to which definitions are relative or absolute is not clear-cut. For instance, whilst it is stated that Class A offices have "above average" rents, it is not made explicit whether the average is for the submarket, metropolitan area or, even, the nation.

Due to perceived subjectivity of the categorization, it is notable that market participants have suggested that a more fine-grained scoring system would provide a clearer signal of quality. This raises a common concern about these types of categories in that they provide little information on the degree of difference within and between groupings. It is possible that, compared to the 'stronger' Class A offices, 'weaker' Class A offices may be much more similar to 'stronger' Class B offices. As a robustness check, we also use an ordered logistic regression to obtain a ratio indicator of asset quality to estimate whether there has been significant differences in the effect of alternative quality indicator over the changing market regimes. The logistic regression should also provide some useful insights into the 
robustness of Costar's ordinal rankings as reliable signals of quality differences between office buildings.

Our initial econometric procedure is hedonic regression modeling. This is the standard methodology for examining price determinants in real estate research. We use this method in our study primarily to isolate the effect of quality classifications. The hedonic price model takes the following form:

$$
P_{i t}=\propto_{i}+\sum_{i=1}^{I} \beta_{i} X_{i}+e_{i}
$$

where $P_{i t}$ is the observed transaction price of a property $i$ at time $t$ or more specifically the natural log of average sale price per square foot in a given building, $X_{i}$ is a vector of several explanatory locational and physical characteristics of the property, $\beta_{i}$ is a vector of parameters to be estimated and $e_{i}$ is a random error and stochastic disturbance term that is expected be normally distributed with a mean of zero.

To capture the effects of perceived property quality on price, we use a simple binary classification (Class A and non-Class A) as defined by CoStar. A full list of the independent variables is presented in Appendix 1. There are a number of important control variables whose parameters are expected to conform to the results of earlier studies in magnitude and direction. Regarding building age, while we expect a negative relationship, we note that a quadratic relationship has frequently been observed between price and age (Ling and Petrova, 2008). The estimated coefficients 
for the various amenities (parking, bank, gym etc), size and number of stories are expected to be positive. We control for variations in market conditions at the time of sale by including a number of factors to model real estate capitalization rates and capital values. Submarket dummies are used to control for location effects.

\section{Summary Statistics}

Summary statistics are presented in Exhibit I. It is worth re-iterating that our dataset incorporates only offices that have actually been sold and consists almost exclusively of Class A, B and C offices. Class A offices tend to be much larger than Class B and C offices. The typical size of the offices sold tended to remain relatively stable throughout the sample period. A notable exception was the first half of 2009 when the median size of transacted Class A offices decreased dramatically. Similarly, the median age of transacted Class A offices was stable at 18-20 years in all but one of the sub-periods. Again, the outlier was the first half of 2009 when the median age of the transacted properties fell to nine years. This suggests that the sample of transacted Class A properties sold in the first half of 2009 was highly unusual compared to the rest of the sub-periods. Given the fact that this sub-period also had the smallest number of transactions overall, the data are consistent with the interpretation that this was a period of unusual market conditions. It is also worth pointing out once more that a proportion of transactions completed in early 2009 would have been agreed in late 2008 . Until the middle of 2009 , the median occupancy rate for Class A offices tended to be higher than non-Class A offices. Following the crisis period associated with the collapse of Lehmans in September 2008, consistent with increased risk aversion there was a marked increase in the 
median occupancy rate of transacted properties. Indeed, for non-Class A offices, the median occupancy rate for transacted properties was 100\% between July 2009 and December 2010.

In terms of price spreads, without controlling for differences in the characteristics of transacted properties in the sub-periods, prima facie the price spreads seem to change dramatically over the period of analysis. In the period 2004 until 2007, Class A offices tend to sell for approximately 30\%-40\% more than non-Class A offices. In 2008 , this price difference increases substantially. From selling at $\$ 170-\$ 180$ psf in 2005/6, non-Class A offices' sale prices more than halve to $\$ 70-\$ 80$ psf in 2010 . The decline in sales prices of transacted Class A offices is less dramatic. Peaking at the same time at $\$ 237-\$ 238$ psf, the median price falls to $\$ 132$ psf in the first half of 2009 and then recovers to between $\$ 170-\$ 180$ in 2010 . Overall, there is a huge increase in the price difference between Class A and non-Class A buildings following the financial market crisis of 2008. This gap between Class A and non-Class A buildings was at its highest in 2010 following the increase in Class A prices in that period. 
Exhibit I Summary Statistics

\begin{tabular}{|c|c|c|c|c|c|c|c|c|c|c|c|}
\hline & & \multicolumn{2}{|c|}{$\begin{array}{l}\text { Median Sale Price } \\
\qquad \$ \text { psf (real) }\end{array}$} & \multicolumn{2}{|c|}{ Median Age } & & $\begin{array}{l}\text { ian Size } \\
\text { are feet }\end{array}$ & Median Occupancy & $\begin{array}{l}\text { Occupancy } \\
\text { Rate } \\
\%\end{array}$ & \multicolumn{2}{|r|}{$\mathbf{N}$} \\
\hline & & Class A & Non-Class A & Class A & Non-Class A & Class A & Non-Class A & Class A & Non-Class A & Class A & Non-Class A \\
\hline \multirow[t]{2}{*}{2004} & Jan-Jun & 200 & 151 & 18 & 24 & 153,000 & 16,500 & $90 \%$ & $86 \%$ & 93 & 507 \\
\hline & Jul-Dec & 208 & 151 & 18 & 23 & 155,295 & 20,497 & $92 \%$ & $83 \%$ & 170 & 525 \\
\hline \multirow[t]{2}{*}{2005} & Jan-Jun & 217 & 166 & 18 & 25 & 167,067 & 19,219 & $90 \%$ & $80 \%$ & 149 & 566 \\
\hline & Jul-Dec & 238 & 180 & 18 & 23 & 182,530 & 24,021 & $90 \%$ & $81 \%$ & 204 & 640 \\
\hline \multirow[t]{2}{*}{2006} & Jan-Jun & 237 & 170 & 20 & 26 & 180,212 & 22,000 & $87 \%$ & $81 \%$ & 187 & 697 \\
\hline & Jul-Dec & 215 & 164 & 20 & 25 & 194,051 & 24,000 & $88 \%$ & $85 \%$ & 252 & 959 \\
\hline \multirow[t]{2}{*}{2007} & Jan-Jun & 235 & 159 & 20 & 25 & 150,608 & 20,017 & $84 \%$ & $81 \%$ & 241 & 858 \\
\hline & Jul-Dec & 218 & 155 & 20 & 25 & 174,879 & 19,654 & $85 \%$ & $80 \%$ & 203 & 857 \\
\hline \multirow[t]{2}{*}{2008} & Jan-Jun & 229 & 140 & 19 & 26 & 168,295 & 16,385 & $88 \%$ & $83 \%$ & 127 & 728 \\
\hline & Jul-Dec & 183 & 112 & 18 & 25 & 132,629 & 18,004 & $90 \%$ & $83 \%$ & 100 & 580 \\
\hline \multirow[t]{2}{*}{2009} & Jan-Jun & 132 & 84 & 9 & 24 & 85,955 & 15,000 & $87 \%$ & $81 \%$ & 51 & 373 \\
\hline & Jul-Dec & 169 & 90 & 17 & 23 & 129,449 & 12,874 & $95 \%$ & $100 \%$ & 84 & 783 \\
\hline \multirow[t]{2}{*}{2010} & Jan-Jun & 172 & 70 & 20 & 26 & 142,500 & 20,856 & $95 \%$ & $100 \%$ & 149 & 797 \\
\hline & Jul-Dec & 176 & 75 & 20 & 27 & 147,520 & 23,421 & $87 \%$ & $100 \%$ & 175 & 747 \\
\hline
\end{tabular}




\section{Results}

The model specification above was applied for the whole sample period on semiannual samples. The results are summarized in Exhibit II. The results reveal that the estimated coefficients on the variables are of the predicted sign. Features associated with prestige properties such as banking facilities, a concierge, a fitness centre and a restaurant also tend to have a positive and significant effect on sales price. Finally, all else equal, the number of stories in an office building has a significantly positive effect on sale prices. With offices aged 70 and over as the omitted variable, the relative sale price premium associated with younger offices declines relatively smoothly and levels off after 30 years. Possibly due to higher vacancies at initial lease-up, new offices tend to sell at a discount relative to offices that are 70 or older. Similarly, the results indicate that newly renovated offices do not sell at a significant premium due to increased re-positioning and re-leasing risk immediately following a major property refurbishment. It is only a year after a renovation that a significant price premium is obtained. This renovation is not significant after five years. In terms of the other independent variables in the model, we note the positive and statistically significant effect of land area and negative effect of rentable building area.

Turning to the variables of interest, it should be kept in mind that these coefficients represent the pricing premium attached to the Class A quality category compared to the reference category which is properties in Class B and Class C. For the whole 
sample models, Class A indicator variables are highly statistically significant and have the anticipated positive sign. For the whole period, Class A premia of $33 \%$ and $35 \%$ premia are estimated for Class $\mathrm{A}$ in the CoStar and the logistic samples respectively. We then estimate the model for samples sub-divided into semi-annual periods. Since each half-year these premiums are estimated in relation to the same price base (that of Classes B and C), then changes in their spread should reflect changes in the risk attached to these qualities.

For both datasets, the premium for Class A drops in the 'hot' market of 2005 and 2006. The Class A premium decreases from 30-40\% in 2004. For the CoStar sample, the lowest Class A premium is estimated in the latter half of 2006 when it falls to 17\%. For the logistic sample, the lowest spread between Class A and the other categories is estimated for 2005 when a Class A premium of $23 \%$ is observed. Whilst it is 
Exhibit II: Summary results from hedonic regression models

\begin{tabular}{|c|c|c|c|c|c|c|c|c|}
\hline & & \multicolumn{3}{|c|}{ CoStar Ratings } & \multicolumn{4}{|c|}{ Ordered Logistic Ratings } \\
\hline & & Coefficient & $\mathbf{N}$ & Adj R-squared & i & Coefficient & $\mathbf{N}$ & Adj R-squared \\
\hline \multirow{2}{*}{2004} & Jan-Jun & 0.31 & 603 & 0.33 & I & 0.30 & 600 & 0.26 \\
\hline & Jul-Dec & 0.46 & 695 & 0.41 & 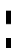 & 0.35 & 690 & 0.32 \\
\hline \multirow{2}{*}{2005} & Jan-Jun & 0.30 & 715 & 0.44 & I & 0.23 & 709 & 0.37 \\
\hline & Jul-Dec & 0.33 & 844 & 0.38 & ! & 0.23 & 844 & 0.28 \\
\hline \multirow{2}{*}{2006} & Jan-Jun & 0.34 & 884 & 0.41 & ! & 0.28 & 884 & 0.36 \\
\hline & Jul-Dec & 0.17 & 959 & 0.42 & I & 0.31 & 961 & 0.41 \\
\hline \multirow{2}{*}{2007} & Jan-Jun & 0.23 & 1099 & 0.42 & I & 0.37 & 1103 & 0.40 \\
\hline & Jul-Dec & 0.31 & 1060 & 0.43 & I & 0.35 & 1054 & 0.38 \\
\hline \multirow{2}{*}{2008} & Jan-Jun & 0.67 & 855 & 0.44 & I & 0.49 & 832 & 0.42 \\
\hline & Jul-Dec & 0.19 & 680 & 0.43 & ! & 0.47 & 666 & 0.34 \\
\hline \multirow{2}{*}{2009} & Jan-Jun & 0.49 & 424 & 0.47 & I & 0.50 & 410 & 0.32 \\
\hline & Jul-Dec & 0.38 & 537 & 0.44 & I & 0.24 & 562 & 0.35 \\
\hline \multirow{2}{*}{2010} & Jan-Jun & 0.60 & 850 & 0.46 & I & 0.43 & 935 & 0.42 \\
\hline & Jul-Dec & 0.53 & 838 & 0.44 & i & 0.50 & 915 & 0.37 \\
\hline All & & 0.33 & 11308 & 0.46 & I & 0.35 & 12684 & 0.50 \\
\hline
\end{tabular}

All coefficients are significant at the $1 \%$ level. 
difficult to be precise due to inherent delays between price agreement and transaction completion, the key turning point is in the latter half of 2007 and the beginning of 2008. For the CoStar sample, the estimated Class A premium increases to $67 \%$ in the first half of 2008 . The comparable estimate for the logistic sample is $49 \%$. Class A spreads remain high in the period following the financial crisis. For both samples, there is a single sub-period following the financial crisis when Class A spreads appear to drop substantially. This occurs in the second half of 2008 for the CoStar sample and in the second half of 2009 for the logistic sample. Detailed investigation of these sub-periods shows sharp drops in sample size and notable changes in the attributes of Class A properties. The low estimates for Class A spreads in these particular sub-periods seem to be an artifact of abnormal and relatively small samples.

\section{Conclusions}

This paper has used sales transaction data in order to examine whether flight from risk phenomena took place in the US office property market following the financial crisis that started in 2007. Within this context, we investigated the effect of the crisis on the pricing of property quality attributes, mainly summarized by the class category of each building. A review of the literature on flight from risk quality and capital flows produced no clear expectations about changes in turnover. A flight from risk can be associated with a change in the marginal investor for an asset class manifested in this context in the substitution of bonds for real estate. Alternatively, within the real estate asset class, capital may be reallocated between different 
qualities of assets. It is a stylized fact of commercial real estate markets that overall market turnover tends to decrease in a falling market. It was our expectation that weaker credit conditions and an increase in risk aversion would have stronger negative effects on lower quality assets both in terms of prices and transaction volumes.

Our results are consistent with the hypothesis of an increased price spread following a market downturn between Class A and non-Class A offices. The evidence suggests that the relationships between the returns on Class A and non-Class A assets changed during the period of market stress or crisis. This finding is robust between different approaches to categorizing Class A and non-Class A assets. There is also clear evidence that the type of assets sold changed significantly when the market crisis was at its worst.

These findings have implications for real estate portfolio construction. If regime switches can be predicted and/or responded to rapidly, portfolios may be rebalanced. In crisis periods, portfolios might be reweighted towards Class A properties and in positive market periods, the reweighting would be towards non-Class A assets. However, it is obviously important to bear in mind the difficulties created by low liquidity in implementing such strategies. Decomposing the drivers of the change in price spread is beyond the scope of this paper. With the existing data, it is not possible to distinguish the extent to which the change in price spread was due to an increase in risk aversion of the marginal investor relative to a change in the 
inherent riskiness of the assets. Future research may seek to identify the factors driving the changes in spread.

Acknowledgments: The authors wish to thank the CoStar Group for providing a large database of property transactions to enable this research. Franz Fuerst also wishes to acknowledge the generous support of the Cambridge University Land Society (CULS). 


\section{References}

Barrios, S., P. Iversen, M. Lewandonwska and R. Setzer. 2009. Determinants of Intra-Euro Area Government Bond Spreads During the Financial Crisis. European Economic Papers 388.

Collett, D. Lizieri, C. and Ward, C. 2003. Timing and Holding Periods of Institutional Real Estate, Real Estate Economics, 31,2, 205-222

Durand, R. B., M. Junker and A. Szimayer. 2010. The Flight-to-Quality Effect: A Copula-Based Analysis. Accounting and Finance 50:281-299.

Fisher, J., D. Gatlaff, D. Geltner and D. Haurin. 2004. An Analysis of the Determinants of Transaction Frequency of Institutional Commercial Real Estate Investment Property. Real Estate Economics 32: 239-264.

Guilkey, D. Miles, M. and Cole, R. (1989) The Motivation for Institutional Real Estate Sales and Implications for Asset Class Returns, AREUEA Journal, 17, 1, 7082

Hartmann, P. S. Straetmans and C. G. De Vries. 2004. Asset Market Linkages in Crisis Periods. The Review of Economics and Statistics 86:313-326.

Johnson, K. H., J. D. Benefield, and J. A. Wiley. 2007. The Probability of Sale for Residential Real Estate. Journal of Housing Research 16:131-142.

Ling, D and Petrova, M. 2008. Avoiding taxes at any costs: The economics of tax deferred real estate exchanges. Journal of Real Estate Finance and Economics, 367404.

Pilpack, J. And S. Straetmans. 2010. Comovements of Different Asset Classes During Market Stress. Pacific Economic Review 15:385-400.

Shiller, R. 1998. Comment on Vincent Warther, "Has the rise of mutual funds increased market instability?" Brooking-Wharton Papers.

Vayanos, D. 2004 Flight to quality, flight to liquidity, and the pricing of risk. NBER Working Papers No. 10327. National Bureau of Economic Research, Inc, London, UK.

Zheng, L. 1998. Who moves the market? Working Paper, University of Michigan Business School. 


\section{Appendix 1}

\begin{tabular}{|c|c|}
\hline \multicolumn{2}{|r|}{ Description of variables } \\
\hline $\begin{array}{l}\text { Independent } \\
\text { variables }\end{array}$ & \\
\hline Age & is a binary variable set to indicate one at a given age of property. \\
\hline Renovated & $\begin{array}{l}\text { is a binary variable set to indicate one at a given number of years since } \\
\text { major refurbishment. }\end{array}$ \\
\hline Sale price & represents the natural logarithm of sale price psf in real terms \\
\hline Occupanc & represents the percentage of the building that is leased \\
\hline Size & represents the natural logarithm of the rentable building area \\
\hline Stories & is the natural logarithm of the number of stories \\
\hline Plot size & $\begin{array}{l}\text { represents the natural logarithm of the area of the site on which the } \\
\text { building is situated }\end{array}$ \\
\hline Class A & $\begin{array}{l}\text { is a binary variable set to indicate one if the property is categorized as } \\
\text { Class A. }\end{array}$ \\
\hline Single tenant & is a binary variable set to indicate one if the property is single-tenanted \\
\hline Bank & $\begin{array}{l}\text { is a binary variable set to indicate one if the property has a bank branch } \\
\text { or ATM in the building }\end{array}$ \\
\hline Fitness center & is a binary variable set to indicate one if the property has a gym \\
\hline Airconditioning & $\begin{array}{l}\text { is a binary variable set to indicate one if the property is completely air- } \\
\text { conditioned. }\end{array}$ \\
\hline Onsite manager & $\begin{array}{l}\text { is a binary variable set to indicate one if the property has a manager's } \\
\text { office }\end{array}$ \\
\hline Bus stop & $\begin{array}{l}\text { is a binary variable set to indicate one if the property is within walking } \\
\text { distance of a bus stop. }\end{array}$ \\
\hline Commuter rail & $\begin{array}{l}\text { is a binary variable set to indicate one if the property has direct access to } \\
\text { or, if in the suburbs, is within reasonable walking distance of a commuter } \\
\text { rail stop }\end{array}$ \\
\hline Conference suite & $\begin{array}{l}\text { is a binary variable set to indicate one if the property has conference } \\
\text { facilities }\end{array}$ \\
\hline Convenience & $\begin{array}{l}\text { is a binary variable set to indicate one if the property has a convenience } \\
\text { store }\end{array}$ \\
\hline Atrium & $\begin{array}{l}\text { is a binary variable set to indicate one if the property has a lobby with a } \\
\text { high, vaulted ceiling or a grand, central court that separates two halves } \\
\text { of a large building }\end{array}$ \\
\hline Bank & $\begin{array}{l}\text { is a binary variable set to indicate one if the property has banking } \\
\text { facilities in the building }\end{array}$ \\
\hline Corner lot & $\begin{array}{l}\text { is a binary variable set to indicate one if the property is situated on } \\
\text { corner lot }\end{array}$ \\
\hline Dry cleaner & $\begin{array}{l}\text { is a binary variable set to indicate one if the property has dry cleaning } \\
\text { facilities in the building. }\end{array}$ \\
\hline Food services & $\begin{array}{l}\text { is a binary variable set to indicate one if the property has a cafeteria } \\
\text { facility }\end{array}$ \\
\hline Signage & $\begin{array}{l}\text { is a binary variable set to indicate one if the property has exterior } \\
\text { signage. }\end{array}$ \\
\hline Street parking & is a binary variable set to indicate one if the property has on street \\
\hline
\end{tabular}




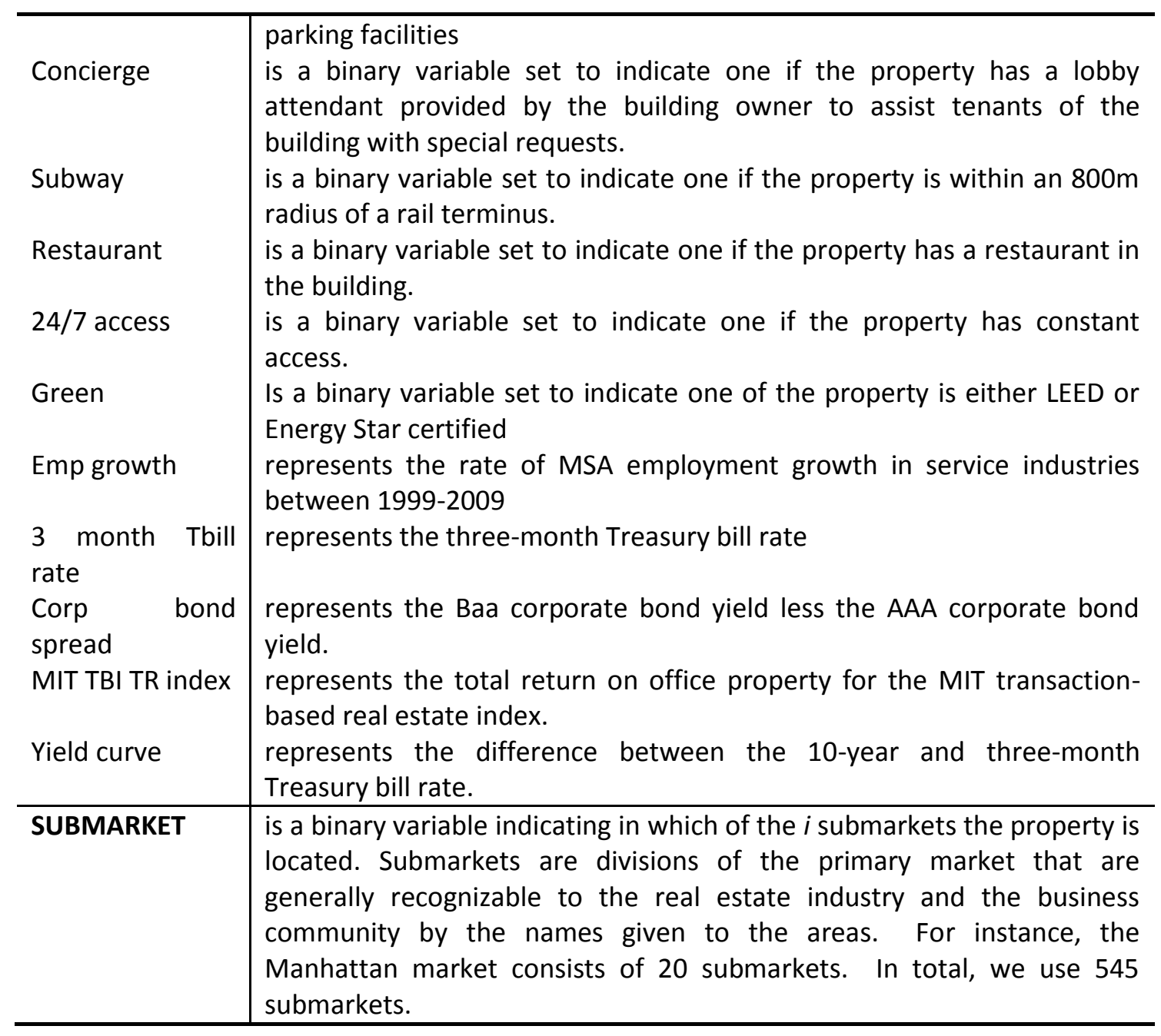




\section{Appendix 2 Hedonic regression results}

\begin{tabular}{|c|c|c|c|c|c|c|}
\hline $\begin{array}{l}\text { Real sale prices (Ic } \\
\text { psf) }\end{array}$ & & $\begin{array}{r}\text { OLS } \\
\text { Coeffic }\end{array}$ & & & & $\begin{array}{l}\text { OLS } \\
\text { fficient }\end{array}$ \\
\hline Constant & & 26.49 & $* * *$ & Size (log) & -0.10 & $* * *$ \\
\hline Class $A$ & & 0.33 & $* * *$ & Stories (log) & 0.003 & \\
\hline$A g e^{1}(y r s)$ & $<1$ & -0.09 & $* * *$ & Plot size (log) & & $* * *$ \\
\hline Age (yrs) & 1 & -0.04 & & Eco-certified & 0.24 & $* * *$ \\
\hline Age (yrs) & 2 & 0.12 & $* * *$ & Bank & 0.07 & $* * *$ \\
\hline Age (yrs) & 3 & 0.02 & & Fitness center & 0.14 & $* * *$ \\
\hline Age (yrs) & 4 & 0.19 & $* * *$ & Onsite manager & 0.03 & $* *$ \\
\hline Age (yrs) & 5 & 0.15 & $* * *$ & Atrium & -0.04 & $* *$ \\
\hline Age (yrs) & 6 & 0.19 & $* * *$ & Bus stop & -0.03 & $* *$ \\
\hline Age (yrs) & 7 & 0.09 & $* *$ & Commuter station & 0.22 & $* * *$ \\
\hline Age (yrs) & 8 & 0.09 & $* *$ & Conference suite & 0.05 & $* *$ \\
\hline Age (yrs) & 9 & 0.09 & $* *$ & Convenience & 0.04 & \\
\hline Age (yrs) & 10 & 0.17 & $* * *$ & Corner lot & 0.01 & \\
\hline Age (yrs) & 11 & 0.02 & & Drycleaner & -0.13 & $* * *$ \\
\hline Age (yrs) & 12 & 0.04 & & Food service & 0.07 & $* * *$ \\
\hline Age (yrs) & 13 & -0.26 & $* * *$ & Signage & 0.01 & \\
\hline Age (yrs) & 14 & 0.06 & & Street parking & 0.10 & \\
\hline Age (yrs) & 15 & -0.05 & & Concierge & 0.11 & $* * *$ \\
\hline Age (yrs) & 16 & 0.02 & & Subway & 0.13 & $* *$ \\
\hline Age (yrs) & 17 & 0.02 & & Restaurant & 0.08 & $* * *$ \\
\hline Age (yrs) & 18 & 0.01 & & $24 / 7$ access & -0.05 & $* *$ \\
\hline Age (yrs) & 19 & -0.09 & $* *$ & Emp growth & 0.34 & $* *$ \\
\hline Age (yrs) & 20 & -0.03 & & Corp bond rate & -7.52 & $* *$ \\
\hline Age (yrs) & 21 & -0.13 & $* * *$ & MIT TBI TR index & 0.004 & \\
\hline Age (yrs) & 22 & -0.06 & $* *$ & MKT dummies & & \\
\hline Age (yrs) & 23 & -0.14 & $* * *$ & & & \\
\hline Age (yrs) & 24 & -0.08 & $* *$ & $R$-squared & 0.63 & \\
\hline Age (yrs) & 25 & 0.04 & & F Test & 33.76 & \\
\hline Age (yrs) & 26 & -0.05 & & F Prob & 0.00 & \\
\hline Age (yrs) & 27 & -0.10 & $* * *$ & No of obs & 11507 & \\
\hline Age (yrs) & 28 & 0.08 & $* *$ & & & \\
\hline Age (yrs) & 29 & -0.04 & & & & \\
\hline Age (yrs) & $30-32$ & -0.09 & $* * *$ & & & \\
\hline Age (yrs) & $33-35$ & 0.01 & & & & \\
\hline Age (yrs) & $36-38$ & -0.09 & $* * *$ & & & \\
\hline Age (yrs) & $39-49$ & -0.11 & $* * *$ & & & \\
\hline Age (yrs) & $50-59$ & -0.07 & $* *$ & & & \\
\hline Age (yrs) & $60-69$ & 0.07 & $* *$ & & & \\
\hline Age (yrs) & $70+$ & Omitted & & & & \\
\hline Renovated (yrs ago) & $0-1$ & -0.13 & $* * *$ & & & \\
\hline Renovated (yrs ago) & $2-3$ & 0.15 & $* * *$ & & & \\
\hline Renovated (yrs ago) & $4-5$ & 0.07 & $*$ & & & \\
\hline Renovated (yrs ago) & $6-10$ & 0.02 & & & & \\
\hline Renovated (yrs ago) & $11-20$ & -0.03 & & & & \\
\hline
\end{tabular}

\footnotetext{
${ }^{1}$ For sale prices, it is the age of the building when sold that is the independent variable.
} 


\section{Appendix 3 CoStar's Office Property Class Definitions}

\section{Class A Office}

In general, a class A building is an extremely desirable investment-grade property with the highest quality construction and workmanship, materials and systems, significant architectural features, the highest quality/expensive finish and trim, abundant amenities, first rate maintenance and management; usually occupied by prestigious tenants with above average rental rates and in an excellent location with exceptional accessibility. They are most eagerly sought by international and national investors willing to pay a premium for quality and are often designed by architects whose names are immediately recognizable. A building meeting this criteria is often considered to be a landmark, either historical, architectural or both. It may have been built within the last 5-10 years, but if it is older, it has been renovated to maintain its status and provide it many amenities. Buildings of this stature can be one-of-a-kind with unique shape and floor plans, notable architectural design, excellent and possibly outstanding location and a definite market presence.

\section{Class B Office}

In general, a class B building offers more utilitarian space without special attractions. It will typically have ordinary architectural design and structural features, with average interior finish, systems, and floor plans, adequate systems and overall condition. It will typically not have the abundant amenities and location that a class A building will have. This is generally considered to be more of a speculative investment. The maintenance, management and tenants are average to good, although, Class B buildings are less appealing to tenants and may be deficient in a number of respects including floor plans, condition and facilities. They therefore attract a wide range of users with average rents. They lack prestige and must depend chiefly on lower price to attract tenants and investors. Typical investors are some national but mostly local.

\section{Class C Office}

In general, a class $C$ building is a no-frills, older building that offers basic space. The property has below-average maintenance and management, a mixed or low tenant prestige, and inferior elevators and mechanical/electrical systems. As with Class B buildings, they lack prestige and must depend chiefly on lower price to attract tenants and investors.

\section{Class F Office}

A functionally or economically obsolete building is one that does not offer a viable alternative for space and does not "compete" with others of similar type for occupancy by businesses seeking a location for operations. These buildings will usually have externally visible physical or structural features as well as internal ones that render it undesirable to be leased and therefore not competitive with any other properties in the market. The property may even be tagged as "Condemned" by the local authorities. 